\title{
Pulmonary pressures at high flows in the intact pulsatile flow perfused lung
}

Pulmonary pressure-flow curves can be easily generated in the intact animal by using a combination of systemic arteriovenous (a-v) fistulas and inferior vena cava (IVC) occlusion. By combining this technique with pulmonary artery occlusion, pulmonary pressure-flow curves may be studied over a broader range of pressures than has been previously been done in the intact, resting animal using pulsatile flow. Pressure-flow curves were generated by varying flow through opening and closing of the a-v fistulas in conjunction with inflating and deflating $a$ balloon in the inferior vena cava. The pressure-flow curves were done under two conditions; (1). with both lungs perfused; (2) with the right lung excluded from the circulation (PA occlusion). $P A$ occlusion resulted in no change in alveolar arterial oxygen tension gradient. The pressure-flow relationships for one lung and two lungs were well described by linear equations $\left(r^{2}=0.83\right.$ \pm 0.03 and $0.82 \pm 0.04$ respectively). The slope of the equations increased with PA occlusion $\left(3.6 \pm 0.4 \mathrm{mmHg} \cdot \mathrm{L}^{-1}\right.$ to $5.9 \pm 0.9$ $\left.\mathrm{mmHg} \cdot \mathrm{L}^{-1}\right)$. There was no change in the pressure axis intercept with $P A$ occlusion $(8.34 \pm 0.8 \mathrm{mmHg}$ pre-occlusion and $8.9 \pm$ $1.3 \mathrm{mmHg}$ post-occlusion). It is concluded that the pulmonary pressure-flow relationship is well described by a linear function above a mean pulmonary artery pressure (PAP) of $10-12 \mathrm{mmHg}$.

Des courbes pression-débit pulmonaires peuvent être obtenues facilement chez l'animal intact en utilisant une combinaison de fistules artérioveineuses (a-v) systémiques et d'occlusions de la

\section{Key words}

LUNG: blood flow, pulmonary artery, vascular resistance.

From the Departments of Anaesthesia, Sunnybrook Health Science Center and St. Michael's Hospital, University of Toronto.

Address correspondence to: Dr. Richard F. McLean, Department of Anaesthesia, Sunnybrook Health Sciences Center, 2075 Bayview Avenue, North York, Ontario, Canada, M4N 3M5.

Supported by The Physician Services Incorporated Foundation of Ontario.

Accepted for publication 9th December, 1991.
Richard F. McLean MD FRCPC, William H. Noble MD FRCPC, Michael Kolton MD FRCPC veine cave inférieure (IVC). En combinant cette technique avec l'occlusion de l'artère pulmonaire, les courbes pression-débit pulmonaires peuvent être étudiées sur une gamme plus étendue de pression qu'auparavant chez l'animal intact au repos par l'utilisation d'un débit pulsatile. Les courbes pression-débit ont été produites en variant le débit à travers les fistules a-v à différents degrés d'ouverture et de fermeture, pendant temps qu'un ballon était gonflé puis dégonflé dans la veine cave inférieure. Les courbes pression-débit ont été produites sous deux conditions: 1) avec les deux poumons perfusés ; 2) avec le poumon droit exclu de la circulation (occlusion PA). L'occlusion de la PA n'a produit aucun changement dans le gradient alvéolo-artériel de la tension en oxygène. Les relations pressiondébit pour un ou deux poumons étaient bien décrites par des équations linéaires $\left(r^{2}=0,83 \pm 0,03\right.$ et $0,82 \pm 0,04$ respective ment). La pente des équations augmentait avec l'occlusion de la $P A\left(3,6 \pm 0,4 \mathrm{mmHg} \cdot L^{-1} \grave{a} 5,9 \pm 0,9 \mathrm{mmHg} \cdot L^{-1}\right)$. Il n'y avait aucun changement avec l'occlusion de la PA quant à la valeur de l'intersection de la droite avec l'axe de pression $(8,34 \pm 0,8$ $\mathrm{mmHg}$ avant l'occlusion et $8,9 \pm 1,3 \mathrm{mmHg}$ après ('occlusion). En conclusion, la relation pression-débit pulmonaire est bien représentée par une fonction linéaire lorque la pression de l'artère pulmonaire moyenne (PAP) est au-dessus de 10 à 12 $\mathrm{mmHg}$.

Pressure-flow relationships in the pulmonary circulation have been the source of much discussion and interest. ${ }^{1-4}$ Recently, several groups have developed a technique for generating pressure-flow plots in intact animals. Lodato $e t$ $a l .{ }^{5}$ first described this technique in conscious dogs using a permanently implanted pneumatic inferior vena cava (IVC) occluder to vary cardiac output. Ducas ${ }^{6}$ used arteriovenous fistulas to alter cardiac output in unconscious dogs. Lejeune ${ }^{7}$ used a combination of a-v fistulas and an occlusive balloon in the IVC to vary cardiac output. The pressure-flow relationship is described by a linear function with two important components, the slope and the extrapolated pressure axis intercept $(\mathrm{Pi})$ which is higher than the left atrial pressure. The slope of the line represents the change in pressure with a change in flow (incremental resistance), and $\mathrm{Pi}$ is a measure of the mean outflow 


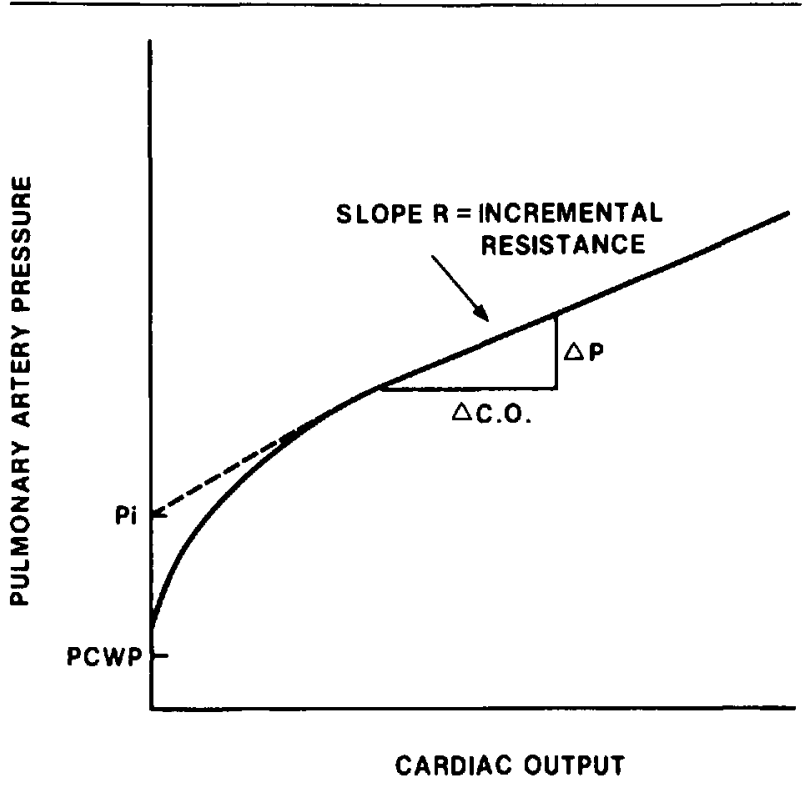

FIGURE 1 An idealized pulmonary pressure flow curve. $X$ axis is cardiac output, $y$ axis pulmonary artery pressure (PAP). At low pressure and flows the relationship between pressure and flow is not linear. As flow increases the relationship becomes linear. The slope of the linear portion ( $R$ ) is the incremental resistance. Extrapolation of the linear portion back to the $y$ axis gives a pressure axis intercept $P i$ which is greater than or equal to PCWP.

pressure of the pulmonary circulation. It, in turn, is dependent on vascular tone, mean airway pressure and left atrial pressure. ${ }^{8-11}$ Figure 1 illustrates an idealized pulmonary pressure-flow curve. While initially not linear, in the range of pressures and flows explored in the intact animal it is linear.

Our interest was to examine pressure-flow curves in intact animals over a higher range of pressures and flows than had been done previously. The above techiques allow the exploration of mean pulmonary artery pressures up to $15-20 \mathrm{mmHg}$ and flows up to $4-6 \mathrm{~L} \cdot \mathrm{min}^{-1}$. By occluding flow to one lung and measuring pressure in the contralateral lung we were able to examine mean pressures up to 28-30 $\mathrm{mmHg}$ and flows up to the equivalent of 8-10 $\mathrm{L} \cdot \mathrm{min}^{-1}$. The pressure-flow relationships of the pulmonary circulation have been examined using in situ perfused lung preparations over a wide range of pressure and flows. ${ }^{3,4}$ The only work analysing the pressure-flow relationships of the pulmonary circulation, over a similiar range, in intact animals with pulsatile flow is that of Lategola. ' Unlike the work in in situ perfused lungs, he suggested that the relationship between pressure and flow was not linear above mean pressures of $20-23 \mathrm{mmHg}$ and flows greater than $250-300 \%$ of normal $\left(\sim 5-6 \mathrm{~L} \cdot \mathrm{min}^{-1}\right)$. The reason for this discrepancy is not clear. It is possible that the pulmonary circulation behaves differently under conditions of pulsatile flow. This technique allowed us to determine if there was a break from linearity at higher pressure and flows in the intact pulsatile flow perfused lung.

\section{Methods}

The experiment was carried out in dogs with the approval of the Animal Investigation Committee of St. Michael's Hospital. Five mongrel dogs $(20-28 \mathrm{~kg})$ were anaesthetized using pentobarbital $25 \mathrm{mg} \cdot \mathrm{kg}^{-1}$ bolus. Anaesthesia was maintained with a pentobarbital infusion at 1-2 $\mathrm{mg} \cdot \mathrm{kg}^{-1} \cdot \mathrm{hr}^{-1}$, and muscle relaxation was provided with pancuronium, $5 \mathrm{mg}$ bolus iv followed by $2 \mathrm{mg}$ bolus q2h. The tracheas were intubated and mechanically ventilated with a volume ventilator, $\mathrm{FIO}_{2} 1.0$, at tidal volumes of $15-20 \mathrm{ml} \cdot \mathrm{kg}^{-1}$ and a rate sufficient to maintain the $\mathrm{PaCO}_{2}$ in the range of $30-45 \mathrm{mmHg}$. An arterial catheter was placed in the femoral artery via a cutdown to measure mean arterial pressure (MAP), and to analyse arterial blood gases throughout the course of the experiment. A 7F balloon flotation catheter was placed, via cutdown, in the right external jugular vein and floated into position in the pulmonary artery. This allowed measurement of central venous pressure (CVP), mean pulmonary artery pressure (PAP), pulmonary wedge pressure (WP) and thermodilution cardiac output $(\mathrm{CO})$. Five $\mathrm{ml}$ of room temperature saline was used to measure the $\mathrm{CO}$ using an Edwards thermodilution computer. A minimum of three measurements was obtained. All pressure lines were connected to transducers, zeroed to the mid-axillary line. Data were recorded on a Gould ES 1000 eight-channel recorder. Core temperature was maintained in the range of $36-39^{\circ} \mathrm{C}$ throughout the experiment. Two A-V fistulas were created using large bore plastic tubing (14F), one between the femoral artery and vein and one between the carotid artery and external jugular vein.

After placement of the catheters, the animal was turned to a right lateral decubitus position and a left thoracotomy performed. The right pulmonary artery was identified at its origin, dissected free and an umbilical tape placed around it. The umbilical tape was then threaded through a rubber sleeve and then brought out through the incision. Positive pressure ventilation was applied until all visible areas of atelectasis were re-expanded. Haemostasis was achieved, the chest loosely closed and the animal returned to the supine position. Then the animal was heparinized with 100 units $\cdot \mathrm{kg}^{-1}$ of heparin followed by a 50 unit $\cdot \mathrm{kg}^{-1}$ bolus every two hours. A Fogarty occlusion catheter (22F) was placed via a cutdown in the inferior vena cava (IVC).

Pressure-flow curves were generated by varying flow through opening and closing of the A-V fistulas in conjunction with inflating and deflating the IVC balloon. All haemodynamic measurements (MAP, CVP, PAP, WP) and 


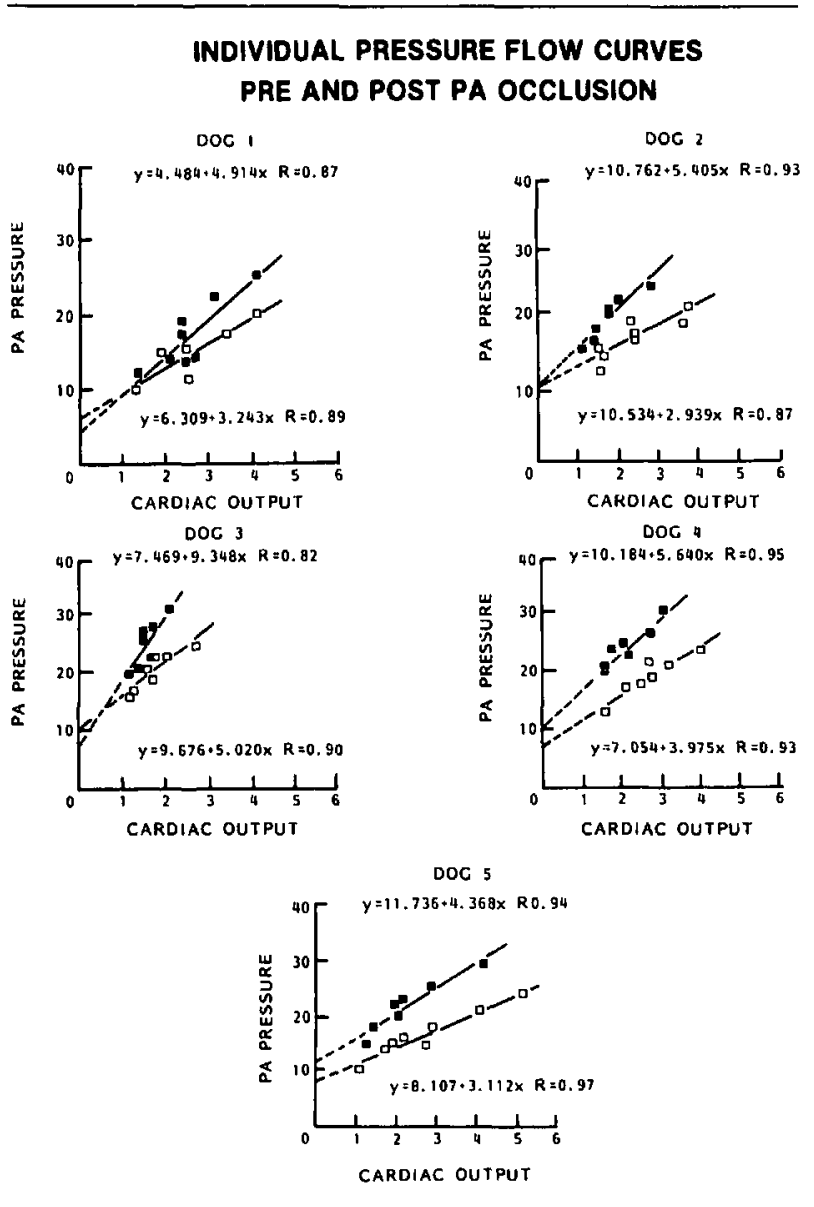

FIGURE 2 PAP versus cardiac output, for individual dogs pre- and post-PA occlusion. $\square=$ pre-PA occlusion, $\square$ = post PA occlusion.

cardiac output determinations were done during a ten second expiratory pause at zero end expiratory pressure. Pulmonary vascular resistance (PVR) was calculated as $80 \times(\mathrm{PAP}-\mathrm{WP}) / \mathrm{CO}$ dyne $\mathrm{sec} \cdot \mathrm{cm}^{-5}$. The pressure-flow curves were done under two conditions, the first with both lungs perfused, and the second with the right lung excluded from the circulation by tightening the previously placed umbilical tape. In all but one dog the pressure-flow curves were generated in the same order, first with two lungs, then with the pulmonary artery occluded. Arterial blood gas analyses were obtained prior to each curve being generated. Alveolar $\mathrm{PO}_{2}$ was approximated assuming a respiratory quotient of 0.8 and an inspired $\mathrm{PO}_{2}=760-47$ $\mathrm{mmHg}$. When the right lung was excluded from the circulation it was necessary to increase the minute ventilation by $25 \%$ to prevent hypercarbia.

\section{Data analysis}

The slope and pressure axis intercepts for each animal in each condition were derived using linear regression. Flow was assumed to be the independent variable and pressure
TABLE I Slopes and intercepts for one lung and two lungs

\begin{tabular}{lllll}
\hline Dog & $\begin{array}{l}\text { Two-lung } \\
\text { slope }\end{array}$ & $\begin{array}{l}\text { One-lung } \\
\text { slope }\end{array}$ & $\begin{array}{l}\text { Two-lung } \\
\mathrm{Pi}\end{array}$ & $\begin{array}{l}\text { One-lung } \\
\mathrm{Pi}\end{array}$ \\
\hline 1 & 3.2 & 4.9 & 6.3 & 4.5 \\
2 & 2.9 & 5.4 & 10.5 & 10.8 \\
3 & 5.0 & 9.3 & 9.7 & 7.5 \\
4 & 4.0 & 5.6 & 7.1 & 10.2 \\
5 & 3.1 & 4.4 & 8.1 & 11.7 \\
Mean \pm SD & $3.7 \pm 0.9$ & $5.9 \pm 1.9$ & $8.3 \pm 1.8$ & $8.9 \pm 2.9$ \\
\hline
\end{tabular}

Units of slope are $\mathrm{mmHg} \cdot$ litre $^{-1} \cdot \mathrm{min}^{-1}, \mathrm{Pi}$ is in $\mathrm{mmHg}$. ${ }^{*} P<0.01$ vs two lungs.

TABLE II $R^{2}$ for regression data

\begin{tabular}{lcc}
\hline Dog & Two lungs $R^{2}$ & One lung $R^{2}$ \\
\hline 1 & 0.795 & 0.764 \\
& $(<0.001)$ & $(<0.001)$ \\
2 & 0.760 & 0.864 \\
& $(<0.001)$ & $(<0.001)$ \\
3 & 0.814 & 0.673 \\
& $(<0.001)$ & $(<0.001)$ \\
4 & 0.852 & 0.897 \\
& $(<0.001)$ & $(<0.001)$ \\
5 & 0.932 & 0.893 \\
& $(<0.001)$ & $(<0.001)$ \\
Mean \pm SD & $0.831 \pm 0.065$ & $0.818 \pm 0.097$ \\
\hline
\end{tabular}

Values in brackets are the $P$ values for the corresponding regression equation.

the dependent variable. The slopes and intercepts under the two conditions were compared using paired t tests. Changes in the alveolar-arterial oxygen tension gradient were analyzed using analysis of variance. The $\mathrm{CO}$ and PCWP values for each dog at minimum, resting and maximum flows were compared utilizing repeated measures analysis of variance. All values are reported as mean \pm standard deviation.

\section{Results}

The pressure-flow curves done with two lungs and with the right lung excluded from the circulation are shown in Figure 2 and the extrapolated intercepts for each of the five animals under the two conditions are recorded in Table I. The slope of the pressure-flow curves increased significantly, while there was no change in $\mathrm{Pi}$ seen with PA occlusion.

Table II shows the $r^{2}$ values for the regression equations under both conditions for each animal. It can be seen that under both conditions the pressure-flow relationships were well described by a linear function. Table III outlines the ranges of flow obtained in each of the five dogs. The minimum and resting $\mathrm{CO}$ were the same for one vs two lungs. The peak flow obtained with two lungs was higher 
TABLE III

\begin{tabular}{|c|c|c|c|c|c|c|}
\hline Dog & $\begin{array}{l}\text { Min CO } \\
\text { one lung }\end{array}$ & $\begin{array}{l}\text { Min CO } \\
\text { two lung }\end{array}$ & $\begin{array}{l}\text { Resting CO } \\
\text { one lung }\end{array}$ & $\begin{array}{l}\text { Resting CO } \\
\text { two lung }\end{array}$ & $\begin{array}{l}\text { Max CO } \\
\text { one ling }\end{array}$ & $\begin{array}{l}\text { Max CO } \\
\text { two lung }\end{array}$ \\
\hline 1 & 1.37 & 1.26 & 2.39 & 2.47 & 4.16 & 4.13 \\
\hline 2 & 1.12 & 1.52 & 1.47 & 2.45 & 2.86 & 3.76 \\
\hline 3 & 1.3 & 1.3 & 1.7 & 1.8 & 2.4 & 3.1 \\
\hline 4 & 1.6 & 1.6 & 2.1 & 2.5 & 3.1 & 4.0 \\
\hline 5 & 1.3 & 1.1 & 2.1 & 2.2 & 4.2 & 5.2 \\
\hline Mean $\pm S D$ & $1.34 \pm 0.17$ & $1.36 \pm 0.20$ & $1.95 \pm 0.365$ & $2.28 \pm 0.30$ & $3.34 \pm 0.80$ & $4.04 \pm 0.76^{*}$ \\
\hline
\end{tabular}

Units are $\mathrm{L} \cdot \mathrm{min}^{-1}$.

$* P<0.05$ vs maximum flow with one lung.

TABLE IV

\begin{tabular}{|c|c|c|c|c|c|c|}
\hline Dog & $\begin{array}{l}\text { Min CO } \\
P C W P \\
\text { one lung }\end{array}$ & $\begin{array}{l}\text { Min CO } \\
P C W P \\
\text { two lung }\end{array}$ & $\begin{array}{l}\text { Resting CO } \\
\text { PCWP } \\
\text { one lung }\end{array}$ & $\begin{array}{l}\text { Resting } C O \\
P C W P \\
\text { two lung }\end{array}$ & $\begin{array}{l}\text { Max CO } \\
P C W P \\
\text { one lung }\end{array}$ & $\begin{array}{l}\text { Max CO } \\
P C W P \\
\text { two lung }\end{array}$ \\
\hline 1 & 5 & 5 & 7 & 6 & 6 & 7 \\
\hline 2 & 5 & 6 & 7 & 7 & 7 & 7 \\
\hline 3 & 6 & 5 & 8 & 6 & 7 & 8 \\
\hline 4 & 4 & 7 & 8 & 10 & 5 & 7 \\
\hline 5 & 6 & 6 & 9 & 9 & 10 & 12 \\
\hline Mean $\pm S D$ & $5.2 \pm 0.84$ & $5.8 \pm 0.84$ & $7.8 \pm 0.84^{*}$ & $7.6 \pm 1.8 \div$ & $7.0 \pm 1.9^{*}$ & $8.2 \pm 2.2 \dagger$ \\
\hline
\end{tabular}

All values are in $\mathrm{mmHg}$.

$* P<0.05$ vs min CO PCWP for one lung.

$\dagger P<0.05$ vs min CO PCWP for two lungs.

than with one lung. Table IV demonstrates the ranges in PCWP under varying conditions. Pulmonary artery occlusion did not affect the PCWP. There was a small but significant rise in PCWP seen with increased flow. Table $V$ shows the range of PAP for each animal under one lung and two lung conditions, with flow ranged from minimum to maximum. The PAP was higher at all flows during PA occlusion. The arterial blood gases and calculated alveolar arterial oxygen tension gradient $\left(\mathrm{P}(\mathrm{A}-\mathrm{a}) \mathrm{O}_{2}\right)$ for one lung vs two lungs and baseline (pre-thoracotomy) are shown in Table VI. While there was a trend for deterioration in gas exchange with thoracotomy, this did not achieve statistical significance. There was no significant change in blood gas parameters seen between one and two lungs.

\section{Discussion}

Pulmonary artery occlusion resulted in an increase in PAP at all levels of flow. No change in the pressure axis intercept was seen with PA occlusion, but incremental resistance increased. The relationship between pressure and flow was well described by a linear function up to PAP's of $25-30 \mathrm{mmHg}$.

These findings confirm what had been found earlier using in situ lung lobes. ${ }^{3,4}$ In these studies the relationship between pressure and flow, while initially curvilinear, became linear above mean perfusion pressures of 15 $\mathrm{mmHg}^{3}$ in one and $27 \mathrm{mmHg}$ in another. ${ }^{4}$ Lodato et al. ${ }^{5}$ described the relationship between pressure and flow in conscious dogs using a chronically implanted hydraulic occluder around the inferior vena cava to regulate cardiac output. They found the relationship between pressure and flow to be linear at flows ranging from 1.5 to $4.5 \mathrm{~L} \cdot \mathrm{min}^{-1}$ and pressures from 4 to $10 \mathrm{mmHg}$. Ducas et al. ${ }^{6}$ also found the relationship to be linear in the range of flows from 1 to $6 \mathrm{~L} \cdot \mathrm{min}^{-1}$ and pressures from 12 to $20 \mathrm{mmHg}$.

Lategola in $1957^{1}$ examined the pulmonary pressureflow relationships in the intact canine lung. This was done by occlusively shifting blood flow within the pulmonary circulation in closed-chested dogs. His data suggested that at PAPs of greater than $20-23 \mathrm{mmHg}$ and flows of greater than $250 \%$ of baseline there was a marked change in the pressure-flow relationship. The pressure increased much more rapidly with increases in flow. The conclusion drawn from this paper was that the small increase in PAP seen with increases in flow of less than $250 \%$ was due to recruitment and distension. After this point the circulation was fully recruited and distended and further increases in flow were associated with much larger increases in pressure.

The values obtained for pressures at the various flows 
TABLE V

\begin{tabular}{|c|c|c|c|c|c|c|}
\hline Dog & $\begin{array}{l}\text { Min CO } \\
\text { PAP } \\
\text { one lung }\end{array}$ & $\begin{array}{l}\text { Min } C O \\
\text { PAP } \\
\text { two lung }\end{array}$ & $\begin{array}{l}\text { Resting CO } \\
\text { PAP } \\
\text { one lung }\end{array}$ & $\begin{array}{l}\text { Resting } C O \\
\text { PAP } \\
\text { two lung }\end{array}$ & $\begin{array}{l}\text { Max CO } \\
\text { PAP } \\
\text { one lung }\end{array}$ & $\begin{array}{l}\text { Max } C O \\
\text { PAP } \\
\text { two lung }\end{array}$ \\
\hline 1 & 12 & 10 & 19 & 15 & 25 & 20 \\
\hline 2 & 16 & 16 & 19 & 18 & 25 & 22 \\
\hline 3 & 19 & 15 & 25 & 20 & 30 & 22 \\
\hline 4 & 19 & 12 & 23 & 17 & 28 & 22 \\
\hline 5 & 15 & 14 & 23 & 16 & 29 & 24 \\
\hline Mean $\pm S D$ & $16.2 \pm 3.0$ & $13.4 \pm 2.4^{*}$ & $21.8 \pm 2.7$ & $17.2 \pm 1.9^{*}$ & $27.4 \pm 2.3$ & $22.0 \pm 1.4^{*}$ \\
\hline
\end{tabular}

All units are in $\mathrm{mmHg}$.

$* P<0.05$ vs one lung.

TABLE VI Blood gas data

\begin{tabular}{lccc}
\hline & Baseline & Two lungs & One lung \\
\hline $\mathrm{pH}$ & $7.40 \pm 0.03$ & $7.36 \pm 0.04$ & $7.31 \pm 0.06$ \\
$\mathrm{PaCO}_{2}$ & $34 \pm 3$ & $36 \pm 6$ & $39 \pm 5$ \\
$\mathrm{PaO}_{2}$ & $537 \pm 83$ & $453 \pm 94$ & $491 \pm 64$ \\
$\mathrm{P}(\mathrm{A}-\mathrm{a}) \mathrm{O}_{2}$ & $133 \pm 84$ & $216 \pm 93$ & $174 \pm 61$ \\
\hline
\end{tabular}

Values are mean $\pm \mathrm{SD}$. The $\mathrm{PCO}_{2}, \mathrm{PO}_{2}$, and $\mathrm{P}(\mathrm{A}-\mathrm{a}) \mathrm{O}_{2}$ are expressed as $\mathrm{mmHg}$.

are compatible with work done by others using in situ lung preparations. Other studies using techniques similiar to ours over a narrower range of flows reported similiar to lower incremental resistances to ours; ${ }^{6,9}$ this probably reflects changes due to thoracotomy and surgical manipulation. Unlike the work of Lategola we found no change in the incremental resistance at higher flows.

This model was chosen because we felt it allowed us to examine the pressure-flow relationships over a wide range without the problems of cannulating and perfusing lung lobes and without necessitating the removal of a portion of the lung. The anaesthetic chosen is not known to have any effects on the pulmonary circulation. The dissection around the main and right pulmonary arteries may have affected the innervation and have resulted in changes in the pulmonary vascular tone. These changes should have been present in both lungs. We were concerned that manipulating the lung during the dissection may have resulted in changes in the vascular tone in the left lung which were not present in the right lung. The pressure axis intercept is a measure of the mean outflow pressure of the pulmonary circulation. It in turn is dependent on vascular tone, mean airway pressure and left atrial pressure. Increases in the tone should increase the pressure required for recruitment and distension and thus increase the pressure axis intercept and vice-versa. The lack of change in the intercept when we went from two lungs to one lung suggests that there was no difference in the pulmonary vascular tone between the two lungs. Incremental resis- tance did increase with PA occlusion which is what would be expected to happen as a result of reducing the crosssectional area of the pulmonary bed.

The outflow pressure, as measured by PCWP did not remain constant. Varying left atrial pressure with flow will affect the slope of the pressure-flow curve ${ }^{12}$ and it could be argued that our inability to maintain a constant outflow pressure affected our results. The change in PCWP seen over the range of flows was small $(1.8 \pm 1.3$ for one lung and $2.4 \pm 2.3$ ) and we do not consider that it affected the results.

Because all measurements were done at zero-end expiratory pressure, the majority of the lung would have been in zone 3 with some zone 2 present in the non-dependent regions of the lung. It would be expected that some recruitment would occur in the zone 2 areas as flow increased, both in the presence and absence of PA occlusion. Distension has been shown to occur through a wide range of pressures, exceeding those explored by us. ${ }^{13-15}$ The linearity of the the curves means that the incremental resistance, as measured by this technique was not affected by the presence of recruitment or distension over the range of pressures and flows studied.

We did not measure flow to the left lung, as a result we do not know the exact distribution of flow between the two lungs. Lategola's work ${ }^{1}$ found that on average $57 \%$ of the cardiac output goes to the right lung and $43 \%$ to the left lung. This also agrees with Craven et al. ${ }^{16}$ who measured the distribution of pulmonary blood flow in supine animals using radioactive microemboli. Assuming our animals were similiar we then scaled the flow data for the one lung condition by multiplying it by a factor of $100 / 43=2.32$. This scaled data was then pooled with the data from two lungs and a composite curve generated. Figure 3 shows the composite pressure-flow curves using the scaled data. The relationship remains linear with a mean $r^{2}$ of $0.781 \pm 0.11$ and a $P<0.001$ in all cases. Maximum scaled $\mathrm{CO}$ ranged from 6 to $10 \mathrm{~L} \cdot \mathrm{min}^{-1}$ this represents an increase in flow of from $271 \%$ to $443 \%$ of resting flow. 
INDIVIDUAL SCALED PRESSURE FLOW CURVES
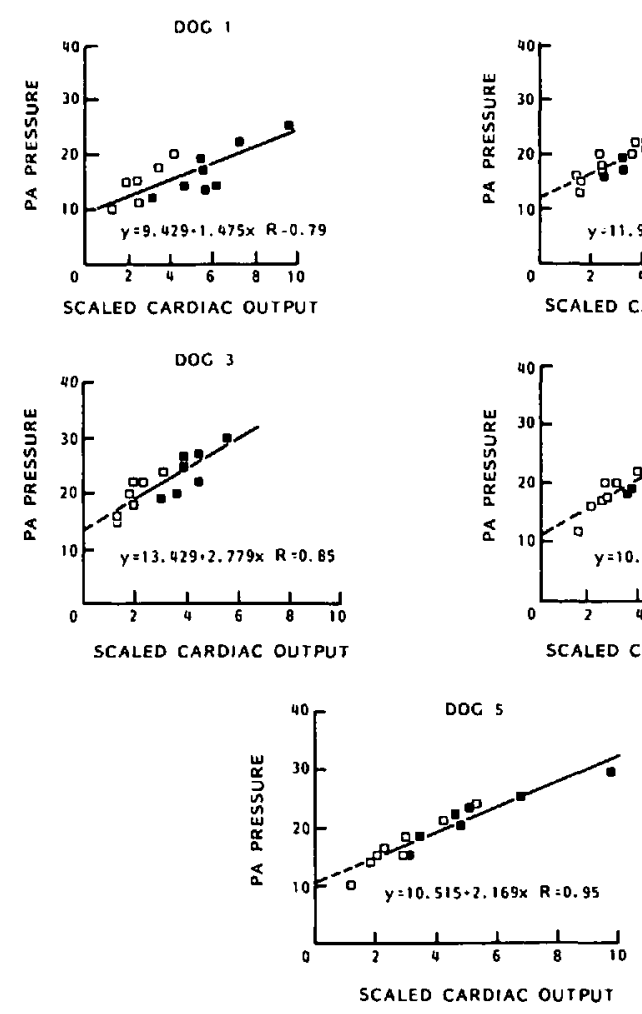

FIGURE 3 PAP versus scaled cardiac output, for individual dogs. Unscaled cardiac outputs for two lungs are pooled with scaled cardiac outputs for one lung. $\square$ Unscaled cardiac output, $\square$ scaled cardiac output.

In summary, we found no change in the incremental resistance of the pulmonary circulation over a broad range of flows and pressures in the intact dog. The pressure-flow relationship is well described by a linear equation above a PAP of $10-12 \mathrm{mmHg}$. These findings are in agreement with previous reports using roller pump perfused in situ lung lobes. We found no evidence of a sudden increase in resistance at pressures greater than $20-23 \mathrm{mmHg}$ or scaled flows greater than $250-300 \%$ of baseline. Incremental resistance as defined by the slope of the pressure-flow curve remained constant.

\section{References}

1 Lategola MT. Pressure flow relationships in the dog lung during acute, subtotal pulmonary vascular occlusion. American Journal of Physiology 1958; 192(3): 613-9.

2 West JB, Dollery CT. Distribution of blood flow and the pressure-flow relations of the whole lung. Journal of Applied Physiology 1965; 20: 175-83.
3 Hyman AL. Effects of large increases in pulmonary blood flow on pulmonary venous pressure. Journal of Applied Physiology 1969; 27(2): 179-85.

4 Fowler NO, Holmes JC. Pulmonary arterial pressure at high pulmonary flow. Journal of Clinical Investigation 1965; 44(12): 2040-50.

5 Lodato RF, Michael JR, Murray PA. Multipoint pulmonary vascular pressure-cardiac output plots in conscious dogs. American Journal of Physiology 1985; 249 (Heart Circ Physiol 18): H351-57.

6 Ducas J, Girling L, Schick U, Prewitt RM. Pulmonary vascular effects of hydralazine in a canine preparation of pulmonary thromboembolism. Circulation 1986; 73(5): 1050-57.

7 Lejeune P, Deloof T, Leeman M, Mélot C, Naeije $R$. Multipoint pulmonary vascular pressure/flow relationships in hypoxic and normoxic dogs: effects of nitrous oxide with and without cyclooxygenase inhibition. Anesthesiology 1988; 68: 92-9.

8 Marshall BE, Marshall $C$. A model for hypoxic constriction of the pulmonary circulation. Journal of Applied Physiology 1988; 64(1): 68-77.

9 Bshouty Z, Younes $M$. Distensibility and pressure-flow relationship of the pulmonary circulation. I. Single-vessel model. Journal of Applied Physiology 1990; 68(4): 1501-13.

10 Bshouty Z, Younes $M$. Distensibility and pressure-flow relationship of the pulmonary circulation. II. Multibranched model. Journal of Applied Physiology 1990; 68(4): 1514-27.

11 Leeman $M$. The pulmonary circulation in acute lung injury: a review of some recent advances. Intensive Care Med 1991; 17: 254-60.

12 Ducas J, Schick U, Girling L, Prewitt RM. Effects of altered left atrial pressure on pulmonary vascular pressureflow plots. Am J Physiol 1988; 255 (Heart Circ Physiol 24): H19-H25.

13 Hanson WL, Emhardt JD, Bartek JP, et al. Site of recruitment in the pulmonary microcirculation. Journal of Applied Physiology 1989; 66(5): 2079-83.

14 Smith JC, Mitzner W. Analysis of pulmonary vascular interdependence in excised dog lobes. Journal of Applied Physiology 1980; 48(3): 450-67.

15 Younes $M$, Bshouty $Z$, Ali $J$. Longitudinal distribution of pulmonary vascular resistance with very high pulmonary blood flow. J Appl Physiol 1987; 62(1): 344-58.

16 Craven $K D$, Oppenheimer $L$, Wood $L D H$. Effects of contusion and flail chest on pulmonary perfusion and oxygen exchange. Journal of Applied Physiology 1979; 47(4): 729-37. 